\title{
Image Quality of Low-Dose Cerebral Angiography and Effectiveness of Clinical Implementation on Diagnostic and Neurointerventional Procedures for Intracranial Aneurysms
}

\author{
(D). Choi, (D) B. Kim, (D)Y. Choi, DN.Y. Shin, (D). Jang, (D) H.S. Choi, (D) S.L. Jung, and (D) K.J. Ahn
}

\begin{abstract}
BACKGROUND AND PURPOSE: Awareness of the potential for exposure to high doses of radiation from interventional radiologic procedures has increased. The purpose of this study was to evaluate image quality and dose reduction of low-dose cerebral angiography during diagnostic and therapeutic procedures for intracranial aneurysms.
\end{abstract}

MATERIALS AND METHODS: A retrospective review of 1137 prospectively collected patients between January 2012 and June 2014 was performed. Beginning in April 2013, a dose-reduction strategy was implemented. Subjective image-quality assessment of 506 standard and 540 low-dose cerebral angiography images was performed by 2 neuroradiologists using a 5-point scale and was tested using noninferiority statistics. Radiation dose-area product and air kerma of 1046 diagnostic and 317 therapeutic procedures for intracranial aneurysms were analyzed and compared between groups before (group 1) and after (group 2) clinical implementation of a dose-reduction strategy.

RESULTS: The image quality of the low-dose cerebral angiography was not inferior on the basis of results from the 2 readers. For diagnostic cerebral angiography, the mean dose-area product and air kerma were $140.8 \mathrm{~Gy} \times \mathrm{cm}^{2}$ and $1.0 \mathrm{~Gy}$, respectively, in group 1 and 82.0 $\mathrm{Gy} \times \mathrm{cm}^{2}$ and $0.6 \mathrm{~Gy}$ in group $2(P<.001, P<.001)$. For the neurointerventional procedure, the mean dose-area product and air kerma were $246.0 \mathrm{~Gy} \times \mathrm{cm}^{2}$ and $3.7 \mathrm{~Gy}$, respectively, in group 1 and $169.8 \mathrm{~Gy} \times \mathrm{cm}^{2}$ and $3.3 \mathrm{~Gy}$ in group $2(P<.001, P=.291)$.

CONCLUSIONS: With low-dose cerebral angiography, image quality was maintained, and implementation of dose-reduction strategies reduced radiation doses in patients undergoing diagnostic and neurointerventional procedures for intracranial aneurysms.

ABBREVIATIONS: $A K=$ air kerma; $\mathrm{DAP}=$ dose-area product

A lthough CT and MR angiography are performed frequently to diagnose cerebrovascular diseases, cerebral angiography is still the criterion standard for the evaluation of the vasculature in cerebrovascular disease, especially when therapeutic procedures are anticipated. The potential for high radiation doses from interventional radiologic procedures is well-known; thus, such procedures should only be performed with adequate justification. ${ }^{1,2}$ The adverse health effects of radiation exposure can be divided into 2 categories: deterministic effects and stochastic effects. Skin dose is related to deterministic effects such as skin erythema, necrosis, ulceration, cataract, and permanent epilation. ${ }^{1,3}$ Although

Received November 22, 2018; accepted after revision February 27, 2019.

From the Department of Radiology (J.C.), St. Vincent's Hospital, College of Medicine, The Catholic University of Korea, Gyeonggi-do, Republic of Korea; and Department of Radiology (B.K., Y.C., N.Y.S., J.J., H.S.C., S.L.J., K.J.A.), Seoul St. Mary's Hospital, College of Medicine, The Catholic University of Korea, Seoul, Republic of Korea.

Please address correspondence to Bum-soo Kim, MD, Department of Radiology, Seoul St. Mary's Hospital, The Catholic University of Korea, 505, Banpo-dong, Seocho-gu, Seoul, 133-701, Korea; e-mail: bumrad@catholic.ac.kr

http://dx.doi.org/10.3174/ajnr.A6029 direct measurement of the skin radiation dose using thermoluminescent dosimeters is the most accurate, it is not practical because it is a cumbersome procedure with limitations. ${ }^{4,5}$ Dose-area product (DAP) and air kerma (AK) are alternative indirect measurements of a patient dose and are the most convenient and currently most widely used parameters for monitoring it. ${ }^{4,6-10}$

With increased awareness of the need for reduction of the radiation dose during cerebral angiography, many techniques and strategies have reduced unnecessary radiation doses while maintaining image quality needed to perform procedures. ${ }^{7-12}$ At Seoul St. Mary's Hospital, we have recorded radiation parameters for each procedure since 2009, and our early experience has shown that the proportion of the radiation dose in terms of DAP from angiographic acquisitions was $88.6 \%$ for diagnostic cerebral angiography and $49.5 \%$ for neurointerventional procedures. ${ }^{6}$ Thus, low-dose angiography provides good image quality and may be an effective way to reduce the radiation dose to patients undergoing diagnostic or neurointerventional procedures. Although there have been several reports showing the effectiveness of low-dose cerebral angiography, little work has been done to study the ap- 
plication and its effectiveness in a clinical setting with a large volume of patients. ${ }^{8,9,13-15}$

Since April 2013, our clinic has implemented the following new dose-reduction strategy: 1) low-dose angiographic protocol (from 3.6 $\mu \mathrm{Gy} /$ frame to $1.8 \mu \mathrm{Gy} /$ frame) for cerebral angiography, and 2) a roadmap image saved for evaluation of the femoral arterial puncture site, instead of femoral angiography. The purpose of this study was to evaluate image quality of low-dose cerebral angiography and the effectiveness of the clinical implementation of our dose-reduction strategies in diagnostic and neurointerventional procedures for intracranial aneurysms.

\section{MATERIALS AND METHODS}

This study was approved by Seoul St. Mary's Hospital institutional review board. A waiver of the need for consent was obtained for this Health Insurance Portability and Accountability Actcompliant retrospective study. Retrospective review of the prospectively collected data base of 1137 patients (799 females, 338 males; median age, 56 years; range, $13-88$ years) between January 2012 and June 2014 was performed. All procedures were per-

Table 1: Mean image quality of angiography by 2 separate readers before and after the low-dose angiographic protocol

\begin{tabular}{lcc}
\hline & Reader 1 & Reader 2 \\
\hline Phase 1 & $4.94 \pm 0.32$ & $4.91 \pm 0.33$ \\
Phase 2 & $4.95 \pm 0.32$ & $4.94 \pm 0.23$ \\
\hline
\end{tabular}
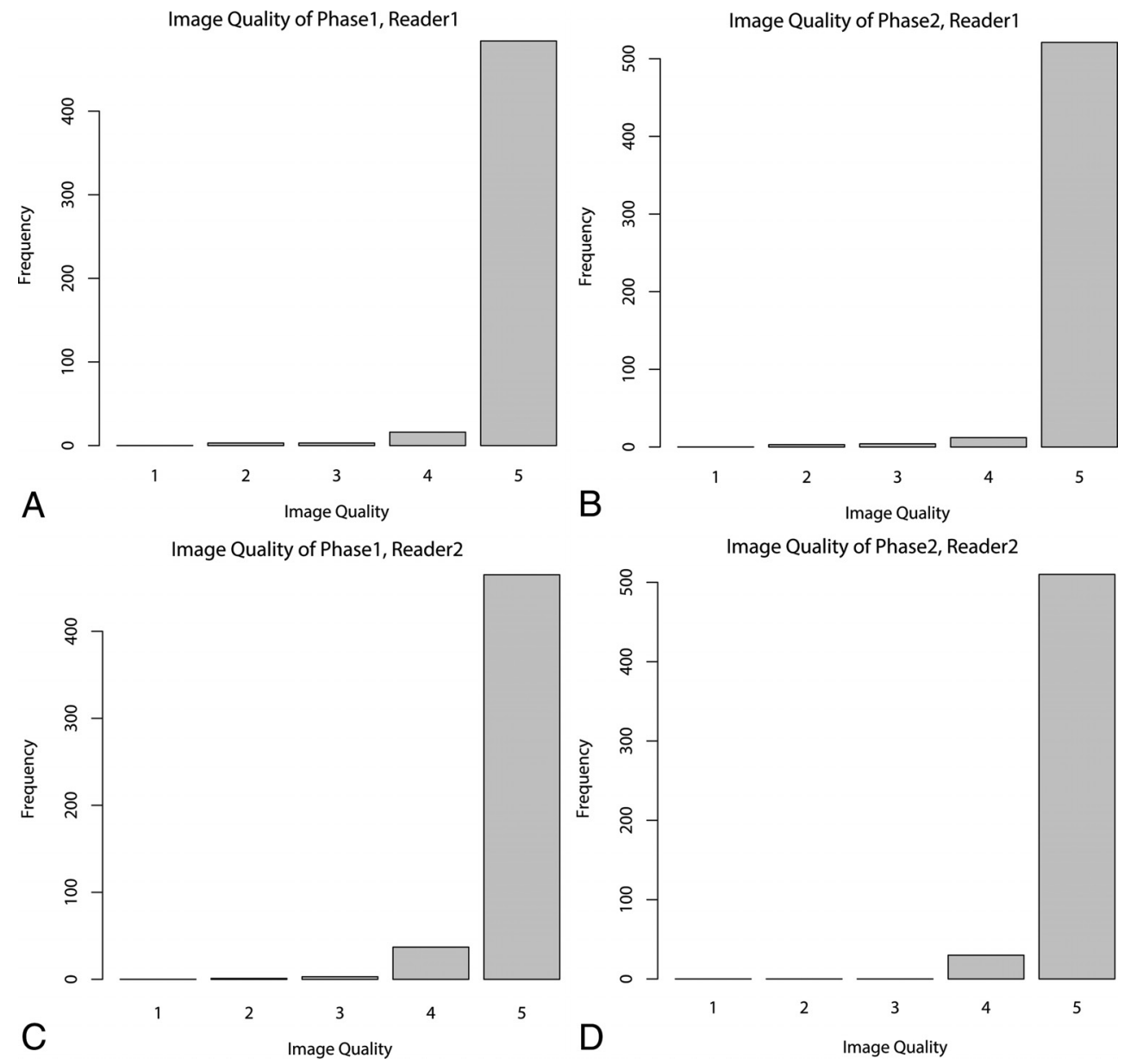

formed by a team of 2 experienced neurointerventionalists. A clinical fellow with $>300$ previous cases performed the diagnostic angiographic procedures, while embolizations were performed by a radiologist with $>20$ years of experience in aneurysm embolization. Diagnostic procedures performed for follow-up after clipping of an aneurysm were excluded. There were, in total, 1046 diagnostic and 317 therapeutic procedures.

The angiographic system used was a biplane angiographic unit (Axiom Artis dBA; Siemens, Erlangen, Germany) with a flat panel detector: A and B planes $(48 \mathrm{~cm})$ with variable FOVs of 42 to $32-22$ to $16 \mathrm{~cm}$. The total filtration was $2.5 \mathrm{~mm} \mathrm{Al}$. The angiography unit had 3 pulsed fluoroscopy modes of 10,15 , and $30 \mathrm{P} / \mathrm{s}$, of which $15 \mathrm{P} / \mathrm{s}$ was used most frequently with variable copper filtration of up to $0.9 \mathrm{~mm}$. The system had a DAP meter, including a verification of the AK and DAP displayed values against an external dosimeter during the quality-assurance process at least once a year.

Since April 2013, our institution has applied the following dose-reduction strategy: 1) low-dose angiographic protocol (from 3.6 $\mu \mathrm{Gy} /$ frame to $1.8 \mu \mathrm{Gy} /$ frame) for cerebral angiography, and 2) a roadmap image saved for evaluation of the femoral artery puncture site, instead of femoral angiography. Angiographic procedures were the same as those used in a previous protocol, including acquisition of internal carotid and vertebral arteriographies in anteroposterior and lateral views, and rotational angiog-

Image Quality of Phase2, Reader2

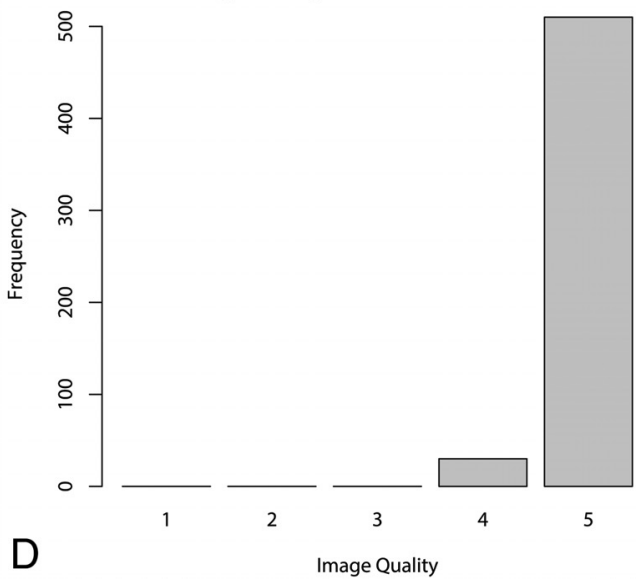

FIG 1. Image quality of angiography by 2 separate readers before (Phase 1) and after (Phase 2) the low-dose angiographic protocol. 

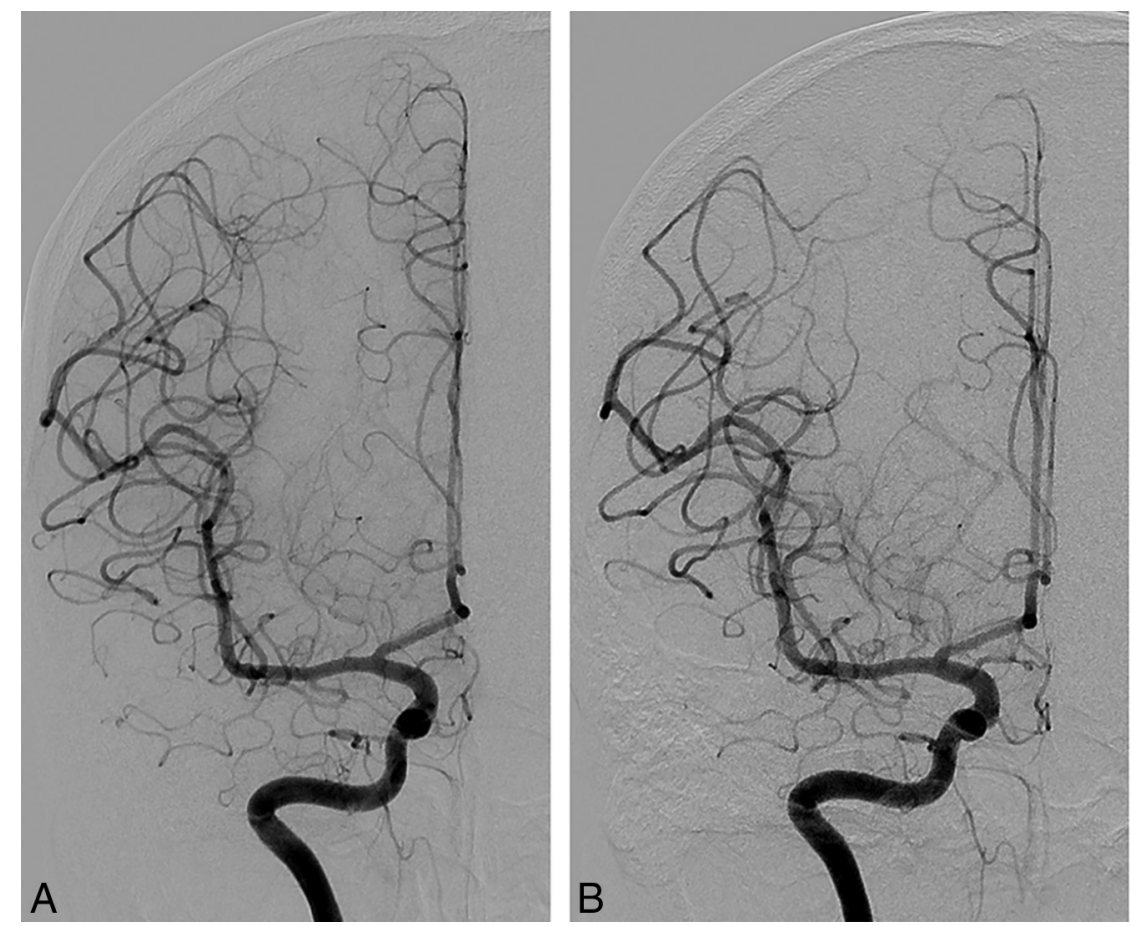

The parameters measured were DAP, AK, fluoroscopy exposure time, and the number of angiographic image acquisitions for all procedures. Image quality was also obtained for 1046 diagnostic procedures (506 procedures before the low-dose protocol and 540 procedures after the low-dose protocol).

A noninferiority test was used for the image quality of diagnostic procedures before and after dose reduction, and interrater reliability was tested using the Cronbach $\alpha$. The difference in parameters before and after the dose-reduction protocol was tested with a Student $t$ test. SPSS (IBM, Armonk, New York) was used for statistical analysis. Statistical significance was defined as $P<.05$.

\section{RESULTS}

The subjective data for the quality of images before and after the low-dose protocol by 2 radiologists are presented in Table 1 and Fig 1. The image-quality score was well-correlated between the 2 observers (Cronbach $\alpha=0.853$ ). The

FIG 2. Representative examples of angiographic images before $(A)$ and after $(B)$ the low-d angiographic protocol. These are cerebral angiograms of a patient who underwent diagnostic angiography to determine the cause of perimesencephalic subarachnoid hemorrhage.

Table 2: Mean and third quartile results for fluoroscopic time, DAP, AK, and image frames for diagnostic and therapeutic procedures before and after the low-dose angiographic protocol

\begin{tabular}{|c|c|c|c|c|}
\hline & $\begin{array}{l}\text { Fluoroscopic } \\
\text { Time (min) }\end{array}$ & $\begin{array}{c}\text { DAP } \\
\left(\mathrm{G} y \times \mathrm{cm}^{2}\right)\end{array}$ & AK (Gy) & $\begin{array}{l}\text { Image } \\
\text { Frames }\end{array}$ \\
\hline \multicolumn{5}{|l|}{ Diagnostic } \\
\hline \multicolumn{5}{|l|}{ Phase 1} \\
\hline Mean & $13.0 \pm 7.9$ & $140.8 \pm 48.1$ & $1.02 \pm 0.42$ & $251.2 \pm 72$ \\
\hline 3rd quartile & 14.4 & 160.8 & 1.18 & 273 \\
\hline \multicolumn{5}{|l|}{ Phase 2} \\
\hline Mean & $11.9 \pm 6.9$ & $82.0 \pm 30.0$ & $0.61 \pm 0.33$ & $222.6 \pm 52$ \\
\hline 3rd quartile & 13.8 & 94.1 & 0.69 & 246 \\
\hline$P$ value & .012 & $<.001$ & $<.001$ & $<.001$ \\
\hline \multicolumn{5}{|l|}{ Therapeutic } \\
\hline \multicolumn{5}{|l|}{ Phase 1} \\
\hline Mean & $53.5 \pm 34.1$ & $246.0 \pm 148.3$ & $3.67 \pm 2.66$ & $287.6 \pm 150$ \\
\hline 3rd quartile & 64.5 & 301.4 & 4.42 & 341 \\
\hline \multicolumn{5}{|l|}{ Phase 2} \\
\hline Mean & $49.1 \pm 32.2$ & $169.8 \pm 111.6$ & $3.31 \pm 3.21$ & $260.2 \pm 128$ \\
\hline 3rd quartile & 60.0 & 206.2 & 4.24 & 334 \\
\hline$P$ value & .237 & $<.001$ & .291 & .080 \\
\hline
\end{tabular}

raphy was performed using 5 -second dual runs with $0.36 \mu \mathrm{Gy} /$ frame when an intracranial aneurysm was suspected on $2 \mathrm{D}$ cerebral angiography. ${ }^{6}$

Two experienced neuroradiologists with $>15$ years of experience evaluated the quality of the images, which had been arranged in a random order. They reviewed all DSA series, and they were blinded to the examination date to avoid knowing the dose category. They analyzed the image quality on a scale of 5 , with the higher number indicating better image quality: 1 (nondiagnostic), 2 (poor: compromised large and small vessel visualization), 3 (average: diagnostic value for large vessel but compromised small vessel visualization), 4 (good: excellent large vessel and minimal compromise of small vessel visualization), 5 (very good: excellent large and small vessel visualization). diagnostic noninferiority of the angiography with $1.8 \mu \mathrm{Gy} /$ frame was demonstrated using the noninferiority test because the upper margin of the 1-sided $97.5 \%$ confidence interval did not cross the predefined noninferiority margin of -0.2 . Figure 2 shows representative examples of the 2 cohorts.

The quantitative data are shown in Table 2 and Fig 3. Before application of the low-dose angiographic protocol (Phase 1), mean fluoroscopic time, total mean DAP, total AK, and total angiographic image frames were $13.0 \pm 7.9$ minutes, $140.8 \pm$ $48.1 \mathrm{~Gy} \times \mathrm{cm}^{2}, 1.02 \pm 0.42 \mathrm{~Gy}$, and $251.2 \pm 72$ frames for diagnostic procedures, respectively, and $53.5 \pm 34.1$ minutes, $246.0 \pm 148.3 \mathrm{~Gy} \times \mathrm{cm}^{2}, 3.67 \pm 2.66 \mathrm{~Gy}$, and $287.6 \pm 150$ frames for therapeutic procedures. The third quartiles, which may be used as a dose reference level, were 14.4 and $64.5 \mathrm{~min}$ utes for fluoroscopy times, 160.8 and $301.4 \mathrm{~Gy} \times \mathrm{cm}^{2}$ for DAP, 1.18 and 4.42 Gy for $\mathrm{AK}$, and 273 and 341 image frames in diagnostic and therapeutic procedures, respectively. After application of the low-dose angiographic protocol (Phase 2), mean fluoroscopic time, total mean DAP, total AK, and total angiographic image frames were $11.9 \pm 6.9$ minutes, $82.0 \pm$ $30.0 \mathrm{~Gy} \times \mathrm{cm}^{2}, 0.61 \pm 0.33 \mathrm{~Gy}$, and $222.6 \pm 52$ frames for diagnostic procedures, respectively, and $49.1 \pm 32.2$ minutes, $169.8 \pm 111.6 \mathrm{~Gy} \times \mathrm{cm}^{2}, 3.31 \pm 3.21 \mathrm{~Gy}$, and $260.2 \pm 128$ frames for therapeutic procedures. The third quartiles, which may be used as a dose reference level, were 13.8 and $60.0 \mathrm{~min}$ utes for fluoroscopy times, 94.1 and $206.2 \mathrm{~Gy} \times \mathrm{cm}^{2}$ for DAP, 0.69 and 4.24 Gy for AK, and 246 and 334 image frames in diagnostic and therapeutic procedures, respectively. There was a significant difference between the mean parameters of fluoroscopic time $(P=.012)$, DAP $(P<.001)$, AK $(P<.001)$, and image frames $(<0.001)$ before and after dose reduction for 

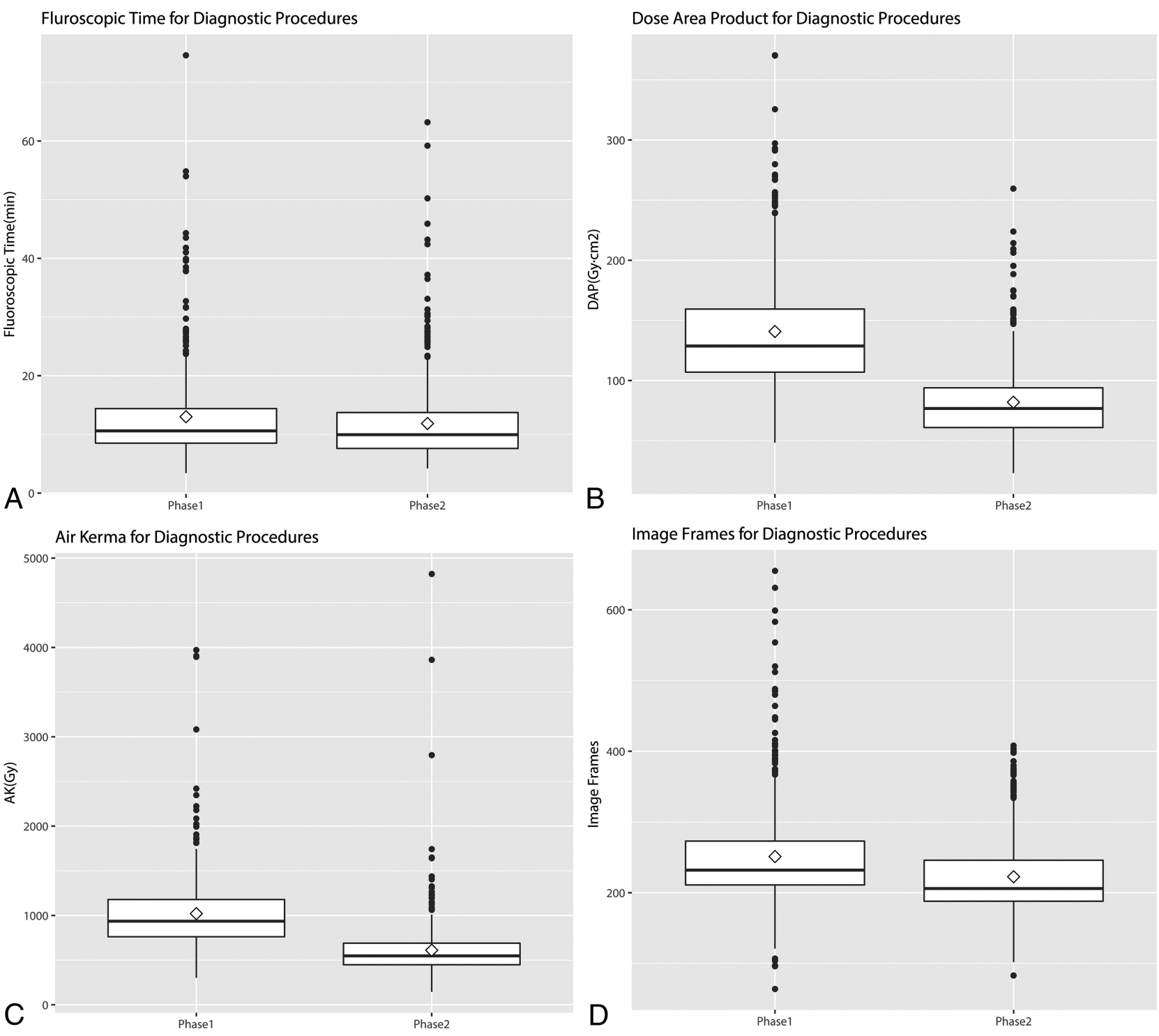

FIG 3. Boxplots of fluoroscopic time, DAP, AK, and image frames for diagnostic and therapeutic procedures before (Phase 1) and after (Phase 2) the low-dose angiographic protocol. Thick horizontal lines indicate median values, and diamonds indicate mean values.

diagnostic procedures. For therapeutic procedures, only the DAP showed a statistically significant difference before and after the dose-reduction protocol $(P<.001)$.

\section{DISCUSSION}

In this study, the subjective image quality of cerebral angiography with $1.8 \mu \mathrm{Gy} /$ frame was not inferior to that with $3.6 \mu \mathrm{Gy} /$ frame. Furthermore, low-dose angiography showed clinically acceptable images with very good image quality of 4.9 of 5 . As in our experience, simple modifications of the default radiation dose have effectively reduced the radiation dose delivered by neurointerventional procedures, but thorough evaluation of image quality in a clinical setting has not been performed. ${ }^{13-15}$ Reducing the radiation dose generally leads to more quantum noise artifacts and edge blurring, which deteriorate image quality. We found that other factors such as blurring caused by patient motion had a greater effect on degradation of image quality than the protocol itself.

Our results showed that the $1.8 \mu \mathrm{Gy} /$ frame protocol can re- duce DAP and AK by $41.8 \%$ and $40.0 \%$, respectively, for diagnostic procedures and by $31.0 \%$ and $10.0 \%$ for therapeutic procedures. They also showed that roadmap saving can reduce the fluoroscopic time and the number of image frames by $8.46 \%$ and $11.39 \%$, respectively, for diagnostic procedures and by $8.22 \%$ and 9.53\% for therapeutic procedures. Our results showed a statistically significant difference of DAP and AK during diagnostic procedures but failed to show a statistically significant difference of AK for therapeutic procedures. This result might be because of the effect of different backscatter radiation, which is sensitive to patient habitus and the effect of different angles of the $\mathrm{x}$-ray beams. The proportion of angiography performed during therapeutic procedures is lower than that during diagnostic procedures ( $49.5 \%$ versus $88.6 \%$ ), and this can neutralize the effect of the low-dose protocol. ${ }^{16}$

Tables 3 and 4 summarize the mean and third quartile data of DAP, fluoroscopic time, and the number of image frames for diagnostic and therapeutic procedures for intracranial aneurysms by various authors. Fluoroscopic time, DAP, and the number of 
Fluroscopic Time for Therapeutic Procedures

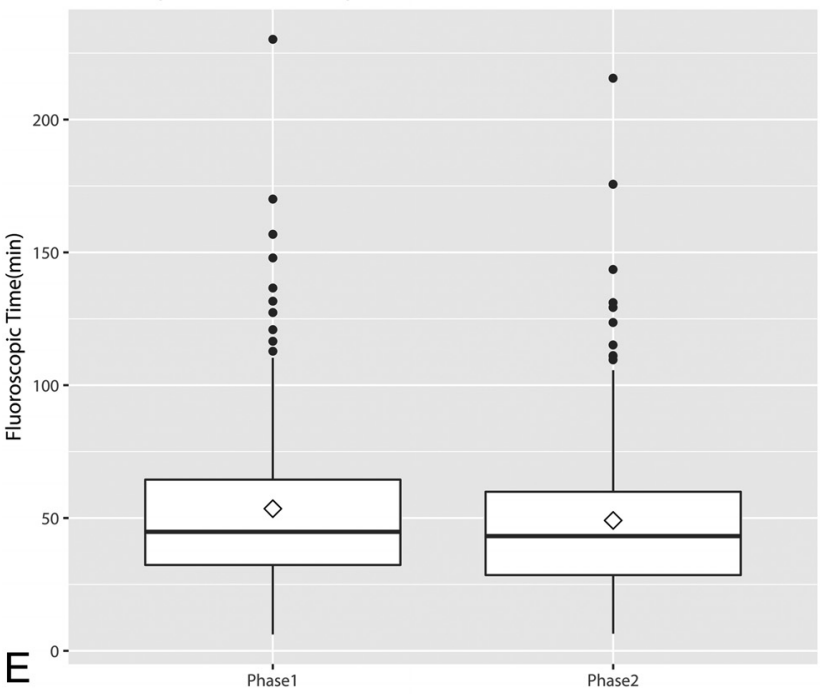

Air Kerma for Therapeutic Procedures

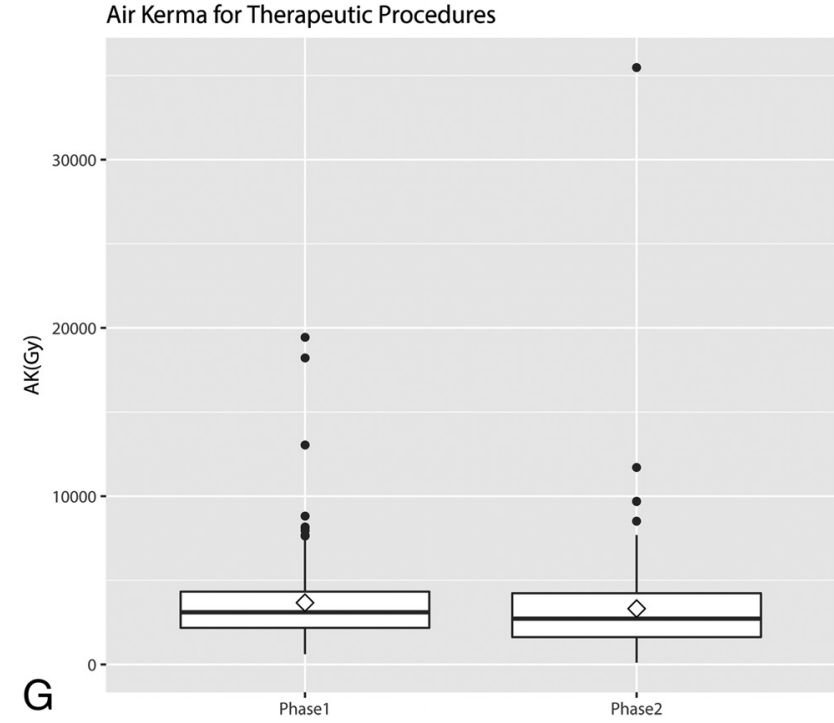

Dose Area Product for Therapeutic Procedures

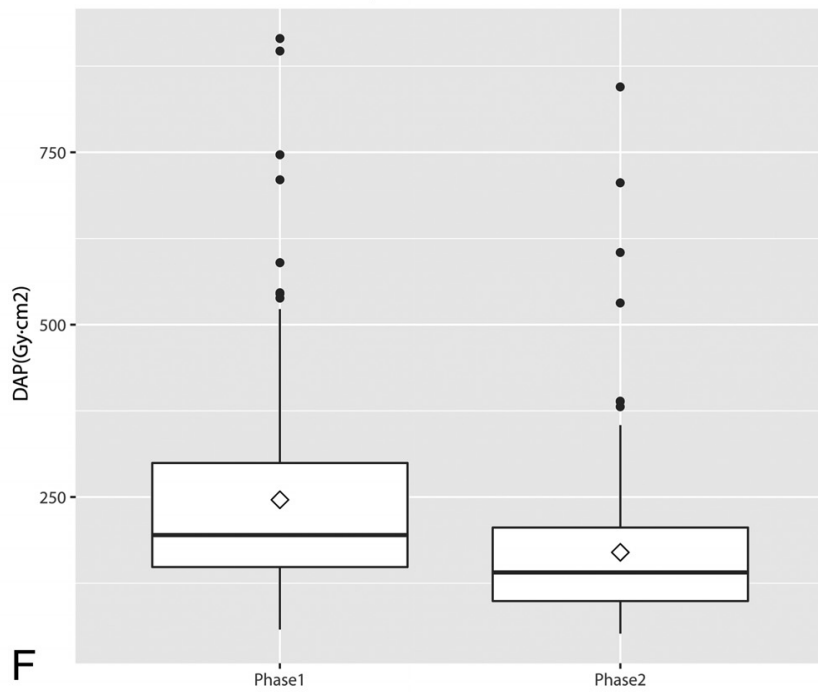

Image Frames for Therapeutic Procedures

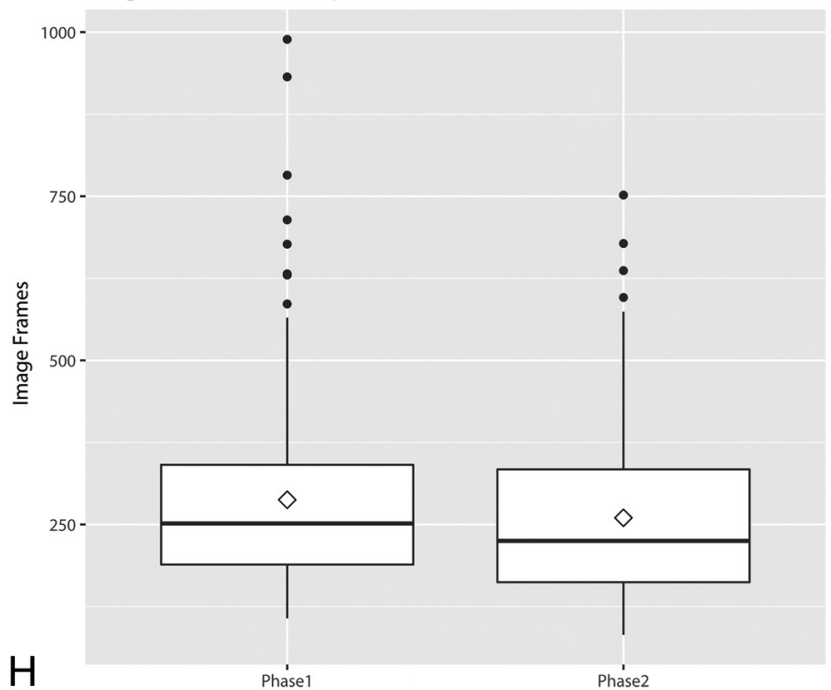

FIG 3. Continued.

Table 3: Summary of mean and third quartile data of DAP, fluoroscopic time, and number of image frames acquired during diagnostic cerebral angiography for intracranial aneurysms

\begin{tabular}{|c|c|c|c|c|c|c|c|}
\hline \multirow[b]{2}{*}{ Reference } & \multirow[b]{2}{*}{ No. of Patients } & \multicolumn{2}{|c|}{$\operatorname{DAP}\left(\mathrm{G} y \times \mathrm{cm}^{2}\right)$} & \multicolumn{2}{|c|}{$\begin{array}{c}\text { Fluoroscopy } \\
\text { Time (min) }\end{array}$} & \multicolumn{2}{|c|}{ No. of Frames } \\
\hline & & Mean & 3rd Quartile & Mean & 3rd Quartile & Mean & 3rd Quartile \\
\hline Phase 1 & 506 & 140.8 & 160.8 & 13.0 & 14.4 & 251.2 & 273 \\
\hline Phase 2 & 540 & 82.0 & 94.1 & 11.9 & 13.8 & 222.6 & 246 \\
\hline Hassan and Amelot ${ }^{17}$ & 398 & 43.1 & 59.7 & 5.6 & 7.5 & 245 & 314 \\
\hline Chun et $\mathrm{al}^{6}$ & 439 & 136.6 & 154.2 & 12.6 & 14.0 & 251 & 273 \\
\hline $\mathrm{D}^{\prime}$ Ercole et $\mathrm{al}^{18}$ & 100 & 142.1 & 180 & 9.9 & 12.3 & 220 & 317 \\
\hline Aroua et $\mathrm{al}^{19}$ & 91 & 121 & 125 & 12.6 & 15 & 679 & 480 \\
\hline Verdun et $\mathrm{al}^{20}$ & 91 & 107 & 124 & & & & \\
\hline Brambilla et $a^{21}$ & 188 & 158 & 198 & 13.7 & 17.5 & & \\
\hline
\end{tabular}

image frames before the low-dose protocol of this study are similar to those from the previous results, except for the report of Hassan and Amelot, ${ }^{17}$ in which the most recent angiographic system was used. ${ }^{6,18-21}$ Our study is especially meaningful in that dose reduction was achieved without purchasing a new angiographic system with sophisticated functions.

We evaluated the DAP instead of the entrance skin dose in our study. The DAP is the absorbed radiation dose multiplied by the size of the area irradiated. ${ }^{22}$ This value can be used to monitor radiation exposure levels and is readily available because it can be easily measured using an ionization chamber in fluoroscopic and angiographic units, and the effective dose can be calculated from it using conversion factors. ${ }^{22}$ Even though the precise prediction of the skin dose using DAP is difficult because $\mathrm{x}$-ray beams enter 
Table 4: Summary of mean and third quartile data of DAP, fluoroscopic time, and number of image frames acquired during therapeutic cerebral angiography for intracranial aneurysms

\begin{tabular}{|c|c|c|c|c|c|c|c|}
\hline \multirow[b]{3}{*}{ Reference } & \multirow[b]{3}{*}{ No. of Patients } & \multirow{2}{*}{\multicolumn{2}{|c|}{ DAP $\left(G y \times \mathrm{cm}^{2}\right)$}} & \multirow{2}{*}{\multicolumn{2}{|c|}{$\begin{array}{l}\text { Fluoroscopy } \\
\text { Time (min) }\end{array}$}} & \multirow{2}{*}{\multicolumn{2}{|c|}{ No. of Frames }} \\
\hline & & & & & & & \\
\hline & & Mean & 3rd Quartile & Mean & 3rd Quartile & Mean & 3rd Quartile \\
\hline Phase 1 & 144 & 246.0 & 301.4 & 53.5 & 64.5 & 287.6 & 341 \\
\hline Phase 2 & 173 & 169.8 & 206.2 & 49.1 & 60.0 & 260.2 & 334 \\
\hline Hassan and Amelot ${ }^{17}$ & 71 & 78.7 & 111.9 & 25.7 & 34.8 & 300 & 428 \\
\hline Chun et $\mathrm{al}^{6}$ & 111 & 226.0 & 272.8 & 52.9 & 61.1 & 241 & 276 \\
\hline $\mathrm{D}^{\prime}$ Ercole et $\mathrm{al}^{18}$ & 72 & 382.2 & 487 & 37.2 & 46.3 & 558 & 717 \\
\hline Aroua et $\mathrm{al}^{19}$ & 52 & 335 & 440 & 36.5 & 50 & 760 & 800 \\
\hline Verdun et $\mathrm{al}^{20}$ & 58 & 335 & 352 & & & & \\
\hline Brambilla et $\mathrm{a}^{21}$ & 356 & 319.9 & & 87.1 & & 1053 & \\
\hline
\end{tabular}

Table 5: The proportion of DAP contributed by rotational angiography before and after the low-dose protocol ${ }^{\mathrm{a}}$

\begin{tabular}{lcc}
\hline & Phase 1 & Phase 2 \\
\hline Diagnostic & & \\
Total DAP $\left(\mathrm{G} y \times \mathrm{cm}^{2}\right)$ & $140.8 \pm 48.1$ & $82.0 \pm 30.0$ \\
Rotation DAP $\left(\mathrm{Gy} \times \mathrm{cm}^{2}\right)$ & $26.3 \pm 13.4$ & $28.0 \pm 13.7$ \\
Rotations/total DAP & $18.7 \%$ & $34.1 \%$ \\
$\quad$ No. of rotations & $1.49 \pm 2.60$ & $1.44 \pm 0.68$ \\
Therapeutic & & \\
$\quad$ Total DAP $\left(\mathrm{Gy} \times \mathrm{cm}^{2}\right)$ & $246.0 \pm 148.3$ & $169.8 \pm 111.6$ \\
Rotation DAP $\left(\mathrm{Gy} \times \mathrm{cm}^{2}\right)$ & $30.8 \pm 17.0$ & $25.6 \pm 14.3$ \\
Rotations/total DAP & $12.5 \%$ & $15.1 \%$ \\
No. of rotations & $1.58 \pm 0.79$ & $1.33 \pm 0.68$ \\
\hline
\end{tabular}

${ }^{2}$ Data are means and percentages.

the patient in many directions, there is a good correlation between skin dose and DAP. ${ }^{5}$ Thus, DAP can be used to set the action level of radiation that indicates skin exposures necessitating medical follow-up for possible radiation injuries and to refine the nationwide reference level as well. ${ }^{16,23}$

The reduction in the number of image frames in our study was largely due to the use of roadmap saving instead of angiography for femoral arteries. Greater reduction of the radiation dose by reducing the number of frames can be achieved using lower frame rates that still produce acceptable image quality.

Some factors can be adjusted to reduce the radiation dose. Fluoroscopic time is directly related to the radiation dose and is dependent on the operators. We think proficiency in cerebral angiography can reduce fluoroscopic time, especially for therapeutic procedures. Rotational angiography is another factor that can be adjusted. When the radiation dose by angiographic procedures was reduced, the proportion of the radiation dose by rotational angiography increased (Table 5). We think we can further reduce the radiation dose using a low-dose protocol for rotational angiography, the feasibility of which was shown by Pearl et al. ${ }^{11}$ Last, strict control of the FOV to contain only vascular structures can also contribute to reduction of the radiation dose.

There are some limitations in our study. First, it was retrospective. Even though the data base was built prospectively, the study was retrospective and vulnerable to selection bias and information bias. We think that the large number of samples tested overcomes this limitation. Second, the cases analyzed were limited to aneurysms. We used only aneurysms because they are the most frequent vascular disease and can be used as representative cases. However, limiting cases makes it difficult to generalize the results of this study. Third, the DAP we used was a simple summation of angiographic DAP, fluoroscopic DAP, and rotational angio- graphic DAP. In this study, we did not evaluate acquisition and fluoroscopic doses separately because we concentrated on only the effect of the low-dose angiography on the total patient dose. Further studies separately analyzing the 2D angiographic dose, 3D rotational angiographic dose, and fluoroscopic dose would have meaningful results. Fourth, we did not evaluate the radiation dose according to the mode of treatment. Cheung et $\mathrm{al}^{24}$ showed that the mode of treatment can affect the radiation dose, and this might have had a confounding effect on our results.

\section{CONCLUSIONS}

Low-dose cerebral angiography maintained image quality, and implementation of dose-reduction strategies contributed to reduced radiation doses of patients undergoing diagnostic and neurointerventional procedures for intracranial aneurysms.

\section{REFERENCES}

1. Valentin J. Avoidance of radiation injuries from medical interventional procedures, ICRP Publication 85. Ann ICRP 2000;30:7-67 CrossRef

2. Food U, Administration D. Avoidance of serious X-ray-induced skin injuries to patients during fluoroscopically-guided procedures. Med Bull 1994;24:7-17

3. Wagner LK, Eifel PJ, Geise RA. Potential biological effects following high X-ray dose interventional procedures. J Vasc Interv Radiol 1994;5:71-84 CrossRef Medline

4. Mahesh M. Fluoroscopy: patient radiation exposure issues. Radiographics 2001;21:1033-45 CrossRef Medline

5. Suzuki S, Furui S, Matsumaru Y, et al. Patient skin dose during neuroembolization by multiple-point measurement using a radiosensitive indicator. AJNR Am J Neuroradiol 2008;29:1076-81 CrossRef Medline

6. Chun $\mathrm{CW}$, Kim BS, Lee $\mathrm{CH}$, et al. Patient radiation dose in diagnostic and interventional procedures for intracranial aneurysms: experience at a single center. Korean J Radiol 2014;15:844-49 CrossRef Medline

7. Söderman M, Holmin S, Andersson T, et al. Image noise reduction algorithm for digital subtraction angiography: clinical results. $R a-$ diology 2013;269:553-60 CrossRef Medline

8. Söderman M, Mauti M, Boon S, et al. Radiation dose in neuroangiography using image noise reduction technology: a population study based on $\mathbf{6 1 4}$ patients. Neuroradiology 2013;55:1365-72 CrossRef Medline

9. Schneider T, Wyse E, Pearl MS. Analysis of radiation doses incurred during diagnostic cerebral angiography after the implementation of dose reduction strategies. J Neurointerv Surg 2017;9:384-88 CrossRef Medline

10. Honarmand AR, Shaibani A, Pashaee T, et al. Subjective and objective evaluation of image quality in biplane cerebral digital subtraction angiography following significant acquisition dose reduction 
in a clinical setting. J Neurointerv Surg 2017;9:297-301 CrossRef Medline

11. Pearl MS, Torok C, Katz Z, et al. Diagnostic quality and accuracy of low dose 3D-DSA protocols in the evaluation of intracranial aneurysms. J Neurointerv Surg 2015;7:386-90 CrossRef Medline

12. Vano E, Fernandez JM, Sanchez RM, et al. Patient radiation dose management in the follow-up of potential skin injuries in neuroradiology. AJNR Am J Neuroradiol 2013;34:277-82 CrossRef Medline

13. Yi HJ, Sung JH, Lee DH, et al. Analysis of radiation doses and dose reduction strategies during cerebral digital subtraction angiography. World Neurosurg 2017;100:216-23 CrossRef Medline

14. Schneider T, Wyse E, Pearl MS. Analysis of radiation doses incurred during diagnostic cerebral angiography after the implementation of dose reduction strategies. J Neurointerv Surg 2017;9:384-88 CrossRef Medline

15. Kahn EN, Gemmete JJ, Chaudhary N, et al. Radiation dose reduction during neurointerventional procedures by modification of default settings on biplane angiography equipment. J Neurointerv Surg 2016;8:819-23 CrossRef Medline

16. Ihn YK, Kim BS, Byun JS, et al. Patient radiation exposure during diagnostic and therapeutic procedures for intracranial aneurysms: a multicenter study. Neurointervention 2016;11:78-85 CrossRef Medline

17. Hassan AE, Amelot S. Radiation exposure during neurointerventional procedures in modern biplane angiographic systems: a single-site experience. Interv Neurol 2017;6:105-16 CrossRef Medline
18. D’Ercole L, Thyrion FZ, Bocchiola M, et al. Proposed local diagnostic reference levels in angiography and interventional neuroradiology and a preliminary analysis according to the complexity of the procedures. Phys Med 2012;28:61-70 CrossRef Medline

19. Aroua A, Rickli H, Stauffer JC, et al. How to set up and apply reference levels in fluoroscopy at a national level. Eur Radiol 2007;17: 1621-33 CrossRef Medline

20. Verdun FR, Aroua A, Trueb PR, et al. Diagnostic and interventional radiology: a strategy to introduce reference dose level taking into account the national practice. Radiat Prot Dosimetry 2005;114: 188-91 CrossRef Medline

21. Brambilla M, Marano G, Dominietto M, et al. Patient radiation doses and references levels in interventional radiology. Radiol Med 2004;107:408-18 Medline

22. Nickoloff EL, Lu ZF, Dutta AK, et al. Radiation dose descriptors: BERT, COD, DAP, and other strange creatures. Radiographics 2008; 28:1439-50 CrossRef Medline

23. Bogaert E, Bacher K, Lemmens K, et al. A large-scale multicentre study of patient skin doses in interventional cardiology: dose-area product action levels and dose reference levels. Br J Radiol 2009;82: 303-12 CrossRef Medline

24. Cheung NK, Boutchard M, Carr MW, et al. Radiation exposure, and procedure and fluoroscopy times in endovascular treatment of intracranial aneurysms: a methodological comparison. J Neurointerv Surg 2018;10:902-06 CrossRef Medline 